\title{
Japanese Society of Biorheology now publishes the Journal of Biorheology
}

\author{
Naoki Sasaki
}

(C) Japanese Society of Biorheology 2009

I am pleased to announce that the Japanese Society of Biorheology is now publishing the Journal of Biorheology in association with Springer Japan. Under the leadership of Professor S. Oka and Professor E. Fukada, the Japanese Society of Biorheology was founded in 1977, and the first publication of its official journal, the Journal of the Japanese Society of Biorheology, was issued under the editorship of Professor M. Kaibara in 1987. In that journal, in addition to announcements for members, original research works by members were published as peer-reviewed papers. With the increase in the activity of the society, a discussion arose among members about the publication of a new scientific journal.

According to Professor Y. Matsunobu, the character of the Japanese Society of Biorheology is best described by the words "biology" and "rheology" (B\&R), not "biological rheology" or "rheological biology." Researchers from a wide range of fields, including hemorheology, clinical hemorheology, biophysics, biomechanics, and food sciences, have joined the society. The new journal will provide a peer-reviewed forum for publication of original papers by researchers in the field of biorheology.
Accordingly, the Journal of Biorheology is expected to cover the science and application of the deformation and flow properties of biological materials. Clinical sciences related to biorheology are also welcome.

After a few years of discussion by the society's preparation committee, we now have realized the publication of the Journal of Biorheology. The first issue is Volume 23, Number 1 because we regard the Journal of Biorheology as the successor to the Journal of the Japanese Society of Biorheology as the official journal of our society. With this inaugural issue, we have introduced the Editorial Manager and Online First systems. With the former, manuscripts can be submitted and reviewed online. The latter system makes possible the quick publication of accepted articles in electronic form prior to publication of the print version.

I sincerely hope that many excellent manuscripts from all over the world will be submitted to the Journal of Biorheology and that the journal will grow as a distinguished international publication in this field of research.

Naoki Sasaki, Ph.D. Editor-in-Chief, Journal of Biorheology

N. Sasaki $(\bowtie)$

Department of Biological Sciences, Graduate School of Science,

Hokkaido University, Kitaku, Sapporo 060-0810, Japan

e-mail: nasa5131@sci.hokudai.ac.jp 